\title{
Halo traction combined with posterior- only approach correction for cervical kyphosis with Neurofibromatosis-1: minimum 2 years follow-up
}

Hongqi Zhang ${ }^{1 \dagger}$, Ang Deng ${ }^{1,2 \dagger}$, Chaofeng Guo ${ }^{1}$, Zhenhai Zhou ${ }^{1,2}$ and Lige Xiao ${ }^{1,2^{*}}$

\begin{abstract}
Background: Surgical management of cervical kyphosis in patients with NF-1 is a challenging task. Presently, anterior-only (AO), posterior-only (PO) and combined anterior-posterior (AP) spinal fusion are common surgical strategies. However, the choice of surgical strategy and application of Halo traction remain controversial. Few studies have shown and recommended posterior-only approach for cervical kyphosis correction in patients with NF-1. The aim of this study is to evaluate the safety and the effectiveness of halo Traction combined with posterior-only approach correction for treatment of cervical kyphosis with NF-1.
\end{abstract}

Methods: Twenty-six patients with severe cervical kyphosis due to NF-1 were reviewed retrospectively between January 2010 and April 2018. All the cases underwent halo traction combined with posterior instrumentation and fusion surgery. Correction result, neurologic status and complications were analyzed.

Results: In this study, cervical kyphosis Cobb angle decreased from initial 61.3 \pm 19.7 degrees to postoperative $10.6 \pm 3.7$ degrees $(P<0.01$ ), with total correction rate of $82.7 \%$, which consist of $45.8 \%$ from halo traction and $36.9 \%$ from surgical correction. JOA scores were improved from preoperative $13.3 \pm 1.6$ to postoperative $16.2 \pm 0.7(P<0.01)$. Neurological status was also improved. There was no correction loss and the neurological status was stable in mean 43 months follow-up. Three patients experienced minor complications and one patient underwent a second surgery.

Conclusion: Halo traction combined with PO approach surgery is safe and effective method for cervical kyphosis correction in patients with NF-1. A satisfied correction result, and successful bone fusion can be achieved via this procedure, even improvement of neurological deficits can also be obtained. Our study suggested that halo traction combined with PO approach surgery is another consideration for cervical kyphosis correction in patients with NF-1.

Keywords: Neurofibromatosis-1, Cervical kyphosis, Halo traction, Posterior-only approach

\section{Background}

Neurofibromatosis (NF) is an auto somal dominant hereditary disorder that consists of two subtypes: NF-1

\footnotetext{
*Correspondence: colinshaw1991@outlook.com

†Hongqi Zhang and Ang Deng contributed equally to this work.

${ }^{2}$ National Clinical Research Center for Geriatric Disorder, Xiangya Hospital, Central-South University, Changsha, China

Full list of author information is available at the end of the article
}

and NF-2. NF-1 (von Recklinghausen's disease) which is known as the most common form of neurofibromatosis with an incidence of 1 per 3000-4000 people worldwide, is associated with numerous clinical manifestations [1, 2]. Patients with NF-1 may present with a wide variety of clinical manifestations such as café-au-lait spots (over $90 \%$ affected), neurofibromas, Lisch nodules, and various skeletal abnormalities [3]. Spinal deformity is only seen in original author(s) and the source, provide a link to the Creative Commons licence, and indicate if changes were made. The images or other third party material in this article are included in the article's Creative Commons licence, unless indicated otherwise in a credit line to the material. If material is not included in the article's Creative Commons licence and your intended use is not permitted by statutory regulation or exceeds the permitted use, you will need to obtain permission directly from the copyright holder. To view a copy of this licence, visit http://creativecommons.org/licenses/by/4.0/. The Creative Commons Public Domain Dedication waiver (http://creativeco mmons.org/publicdomain/zero/1.0/) applies to the data made available in this article, unless otherwise stated in a credit line to the data. 
the subtype NF-1, and can be divided into two categories: dystrophic pattern and non-dystrophic pattern $[4,5]$.

Kyphosis is the most common deformity that occurs in the cervical spine of patients with NF-1 [6]. Although cervical kyphosis is asymptomatic in most patients with NF-1, it can also cause neck pain with occasional neurological complications like nerve root compromise and complete or incomplete spinal cord deficits, with induced life-threatening paralysis [4]. Some patients with the tendency to have progression of kyphosis and deterioration of neurological function were advised to accept early surgical intervention [7]. Surgical management depends on multiple factors such as patient age, kyphotic angle, flexibility, extent of vertebral dysplasia and neurological status. Presently, anterior-only (AO), posterior-only (PO) and combined anterior-posterior (AP) spinal fusion are common strategies for the management of cervical kyphosis in patients with NF-1 [8-10]. In recent years, single procedure and combined therapies have also been applied in the treatment of cervical kyphosis in patients with NF-1 $[8,9,11]$, however, the choice of surgical strategy remains controversial.

In this study, we evaluated the safety and effectiveness of halo traction combined with posterior-only (PO) approach correction in the treatment of cervical kyphosis in patients with NF-1.

\section{Methods}

\section{Clinical characteristics}

Twenty-six patients with cervical kyphosis due to NF-1 treated in our institution were reviewed retrospectively between January 2010 and April 2018 (Table 1) including 11 males and 15 females, with average age of 16 years (range 7-29years). Each patient presented with typical café-au-lait spots, and were definitely diagnosed with NF-1. Dystrophic changes were observed in 7 patients and 19 patients presented non-dystrophic. The involved cervical segments were from C2 to C7. In this study, 15 patients reflected cervical kyphosis while 11 patients presented additional neurological deficits such as neck pain, asthenia of limbs and positive pathological signs.

\section{Inclusion and exclusion criteria}

The inclusion criteria were as follows: (i) patients who definitive diagnosis of NF-1 and associated cervical kyphosis, cobb angle $>40$ degrees, (ii) patients treat with halo traction combined with posterior-only approach correction, (iii) patients who underwent corrective surgery with a minimum of 2 years of follow-up. The exclusion criteria were as follows: (i) diagnosis of other types of neurofibromatosis, (ii) cervical kyphosis caused by congenital, traumatic, or idiopathic factors, (iii) a history of spine surgery.
Table 1 Patients Demographic

\begin{tabular}{ll}
\hline Gender (M/F) & $11 / 15$ \\
Mean age (yr) & $16.8 \pm 5.5$ \\
Max traction weight (kg) & $3.9 \pm 0.7$ \\
Period of traction (days) & $23.2 \pm 11.4$ \\
Period of follow-up (months) & $43.0 \pm 11.7$ \\
Involved vertebra & \\
C2-C5 & 4 \\
C2-C6 & 4 \\
C3-C5 & 4 \\
C3-C6 & 8 \\
C3-C7 & 4 \\
C4-C6 & 1 \\
C4-C7 & 1 \\
\end{tabular}

\section{Imaging procedure}

The deformity evaluation was performed on the anterior/posterior and lateral cervical radiographs. Dynamic lateral flexion and extension $\mathrm{x}$-ray images and CT scans were also taken to evaluate the overall flexibility of the cervical spine. Magnetic resonance imaging (MRI) of the cervical spine was also obtained in all patients for further investigation of the intraspinal contents and compressive pathological features.

\section{Clinical evaluation}

All patients in this study underwent halo traction combined with posterior fixation and fusion. The indications for surgical intervention in these patients were severe cervical kyphosis impairing movement, mechanical neck pain, different degrees of neurological deficit, or progression of cervical deformity. The neurological function evaluation was based on the JOA scores.

\section{Traction procedure}

All patients underwent local anesthesia for halo placement. Patients were supine in the bed and halo traction applied in patients and started with a parallel traction. Then, a blanket roll was placed under the shoulders and the height was increased gradually. The traction direction was gradually changed from parallel traction to hyperextension traction. The initial traction weight was $2 \mathrm{~kg}$, and it increased subsequently by $0.5 \mathrm{~kg}$ every 3 days reaching maximum traction efficiency. It can be implied that a maximum traction efficiency has been obtained because there was no improvement of kyphotic angle with increasing traction weight or a maximum traction weight that the patient can tolerate has reached (Generally, maximum traction weight is generally less than $1 / 6$ of the patient's weight.). Traction continued till there 
was no significant improvement in Cobb angle on weekly radiographic. Neurological examinations were performed 2 times per day, and if the patient had any complaint during the traction, the traction weight was reduced temporarily with the traction maintained.

\section{Surgical procedure}

Posterior spinal fusion and correction were performed under general anesthesia. The operative procedure was performed under maintained maximum traction weight. The lateral mass screws and/or pedicle screws, hooks were placed at the levels of fixation via a middle incision. Generally, patients with osteoporosis and lower bone mineral density can cause a reduction of screw holding force. It is necessary to insert more mass and/or pedicle screws, hooks, to provide more anchor points, disperse correction force, and stabilize the correction result. It is also necessary to loosen facet joints and posterior column osteotomy (PCO) before correction, including SPOs and Ponte osteotomy. After posterior fixation and kyphosis correction, abundant bone graft (allograft bone and / or autogenous iliac bone) was performed to create conditions for posterior column fusion. Somatosensory evoked potentials (SEP), motor evoked potentials (MEP) and wake-up test were used to evaluate the spinal cord function during operative process. All the patients wore cervicothoracic orthosis for 3 months postoperatively.

\section{Evaluation methods}

In order to evaluate the efficiency of halo traction combined with PO approach surgery for cervical kyphosis correction in patients with NF-1, correction result was measured with Cobb angle and following parameters were used.

Traction correction rate $=($ Pre-Tc Cobb-Post $-\mathrm{Tc}$ Cobb)/Pre-Tc Cobb $\times 100 \%$.

Total correction rate $=($ Pre-Tc Cobb - Post-Op Cobb $) /$ Pre-Tc Cobb $\times 100 \%$.

Surgical correction rate $=$ Total correction rate - Traction correction rate.

$($ Pre-Tc $=$ Pre-Traction, $\quad$ Post-Tc $=$ Post-Traction, Post-Op $=$ Postoperative)

In order to evaluate the safety of halo traction combined with PO approach surgery for cervical kyphosis correction in patients with NF-1, JOA scores were recorded to assess neurological functions.

\section{Statistical analysis}

Data were managed and analyzed using SPSS 17.0. Data were presented with mean $\pm \mathrm{SD}$. A paired sample t-test was used to test for significant differences. A $P$ value $<0.05$ was considered statistically significant.

\section{Results}

\section{Improvement of cobb angle}

All the patients underwent halo traction for 10-61 days. (mean $23.2 \pm 11.4$ days) with maximum weight of $5 \mathrm{~kg}$ (mean $3.9 \pm 0.7 \mathrm{~kg}$ ). Cobb angle decreased from PreTraction (Pre-Tc) $61.3 \pm 19.7$ degrees to Post-Traction (Post-Tc) $33.2 \pm 11.2$ degrees. $P<0.01$. Traction correction rate was $45.8 \%$. Postoperative Cobb angle was $10.6 \pm 3.7$ degrees. Surgical correction rate was $36.9 \%$. All the patients were followed up for mean 43 months. Cobb angle was $9.7 \pm 5.2$ degrees in last follow up (typical case Figs. 1 and 2). There was no correction loss in follow-up. (Table 2).

\section{Improvement of JOA scores}

In this study, 15 patients presented only cervical kyphosis while 11 patients displayed additional neurological deficits. JOA scores improved from preoperative $13.3 \pm 1.6$ to postoperative $15.8 \pm 0.9, \mathrm{P}<0.01$. JOA scores were $16.4 \pm 0.6$ in 2 years follow-up, the neurological status was stable in follow-up. (Table 3).

\section{Complications}

In this study, 3 patients experienced halo pin loosing during traction. One patient underwent a second surgery because of unilateral upper limb paralysis, and the paralysis was fully recovered at 3 months followup. There were no systemic complications, pneumonia, thromboembolism, sepsis and peptic ulcers, which can arise due to prolonged bed rest.

\section{Discussion}

Cervical abnormalities associated with NF-1 include enlarged neural foramina, cervical kyphosis, and gross cervical kyphosis with subluxation or dislocation. Kyphosis is the most common deformity and surgical management of this deformity has received little attention in literature reviews. For cervical kyphosis in NF-1, successful managements require early recognition, a more aggressive and reliable intervention to prevent disastrous worsening of the deformity. Several factors complicate the treatment and they are: i) a potential high risk of spinal cord injury during the correction. ii) difficulties in placing stable anchors in dystrophic vertebrae. iii) difficulty in obtaining solid bone fusion and iv) manipulation of the extreme degree of deformity in the presence of compromised cord may lead to severe cord damages and ischemia [7].Three approaches were recommended to manage cervical kyphosis; Anterior-only (AO) approach, Posterior-only (PO) approach and combined anterior and posterior (AP) approach [10, 12]. Most previous studies have recommended AP approach, while a 


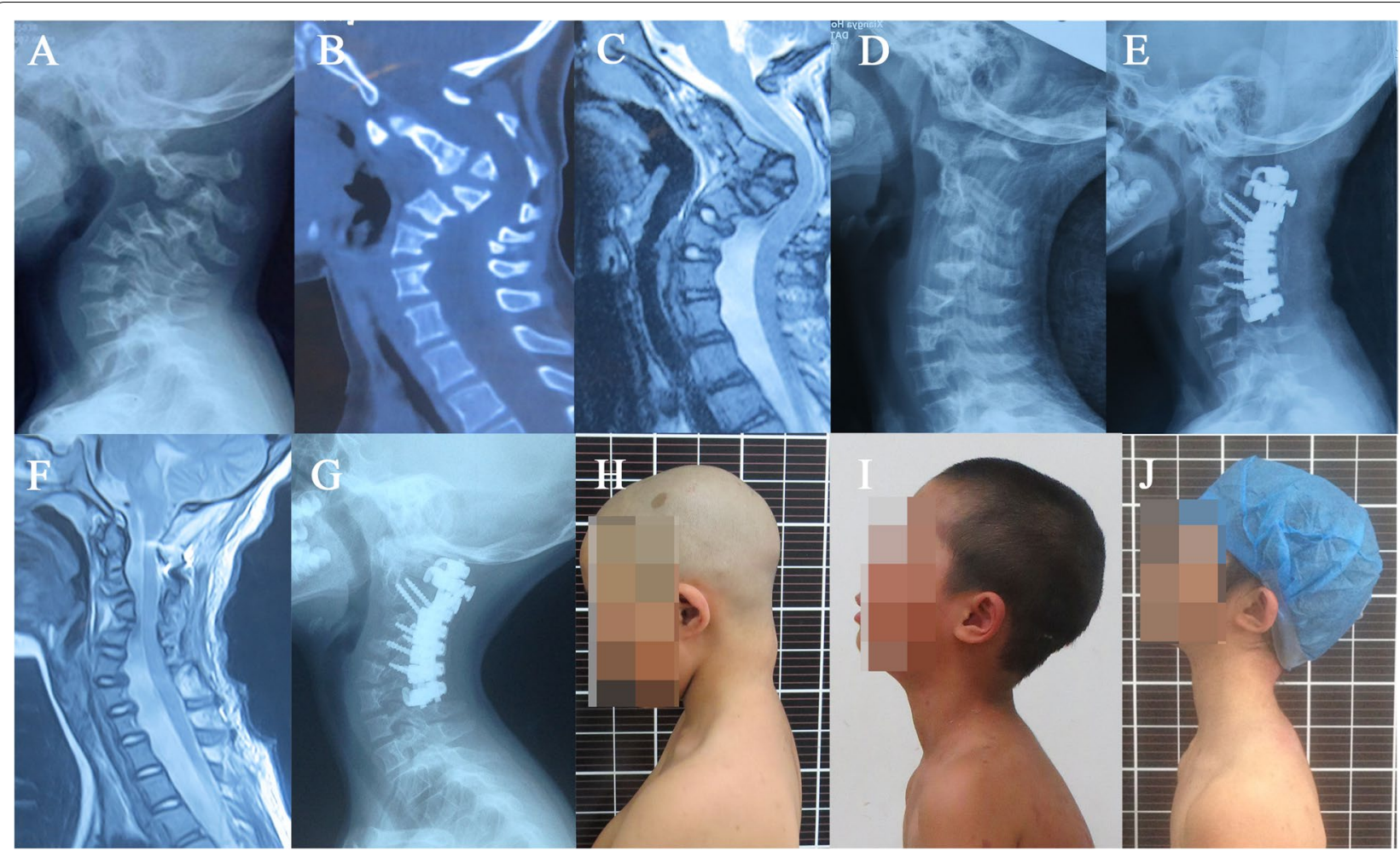

Fig. 1 A 7-year-old case with NF-1 cervical kyphosis. Preoperative JOA score was 14. A-C Preoperative X-rays, CT showed severe kyphosis of $120^{\circ}$ with severe dystrophic changes in cervical spine, and MRI demonstrated a mild compression from kyphosis. D After halo-traction, the kyphotic angle gradually improved from $120^{\circ}$ to $52^{\circ}$. E-F Cercical kyphosis improved to $17^{\circ}$ after surgery, and MRI showed the compression of spinal cord which was decompressed. G X-ray showed a solid bone union and no significant correction loss at follow-up. H-J Pre-op, post-op and latest follow-up clinical photos

few studies have suggested anterior fusion or posterior fusion alone for cervical kyphosis associated with NF-1 because of fusion failure, pseudoarthrosis and correction loss in follow-up [7, 11]. A successful spinal fusion via single approach is fraught with difficulties in NF-1. Several scholars reported a high incidence of fusion failure which from 53 to $72 \%$ [13-16]. Moreover, a 23 and $7.5 \%$ incidence of fusion failure were observed in who managed by AP $[16,17]$. ITherefore, how to manage the fusion failure is a challenge for kyphosis correction in NF-1. It is well known that NF-1 affects bone quality (osteoporosis) and quantity (vertebral body dysplasia) [18]. It is extremely difficult to place stable anchors where there are severe dystrophic changes in the cervical spine $[19,20]$. Without stable anchors, the correction will eventually be suboptimal. Moreover, the other surgical challenge seen in NF-1 is lower bone mineral density (BMD). It has been reported that decreased bone BMD in both sexes at an early age is up to $50 \%$ of individuals with NF-1 [19]. Therefore, dystrophic and osteoporotic vertebral bodies may be insufficient to hold screws. Furthermore, preoperative halo traction can also have a negative impact on the BMD [21]. In this study, halo traction combined $\mathrm{PO}$ approach correction was used for the treatment of cervical kyphosis in patients with NF-1. In order to achieve stable fixation and successful bone fusion via PO approach, two points, more anchor points and abundant bone graft, in the operation are particularly important. More lateral mass and/or pedicle screws, hooks, even short screws, could provide more anchor points, which could disperse correction force and stabilize the correction result. Additionally, Abundant bone graft (allograft bone and / or autogenous iliac bone) was adopted to provide enough solid support for a successful bone fusion. As a result, the correction result was stable and bone fusion was successful in follow-up. After the operation, all the patients wore a cervicothoracic orthosis for 3 months, postoperative external fixation is mandatory to maintain the correction and to obtain solid bone union. Our study showed that with support of more anchors, abundant bone graft and postoperative external fixation, a stable fixation and successful bone fusion can be achieved via PO approach for cervical kyphosis correction in patients with NF-1. 


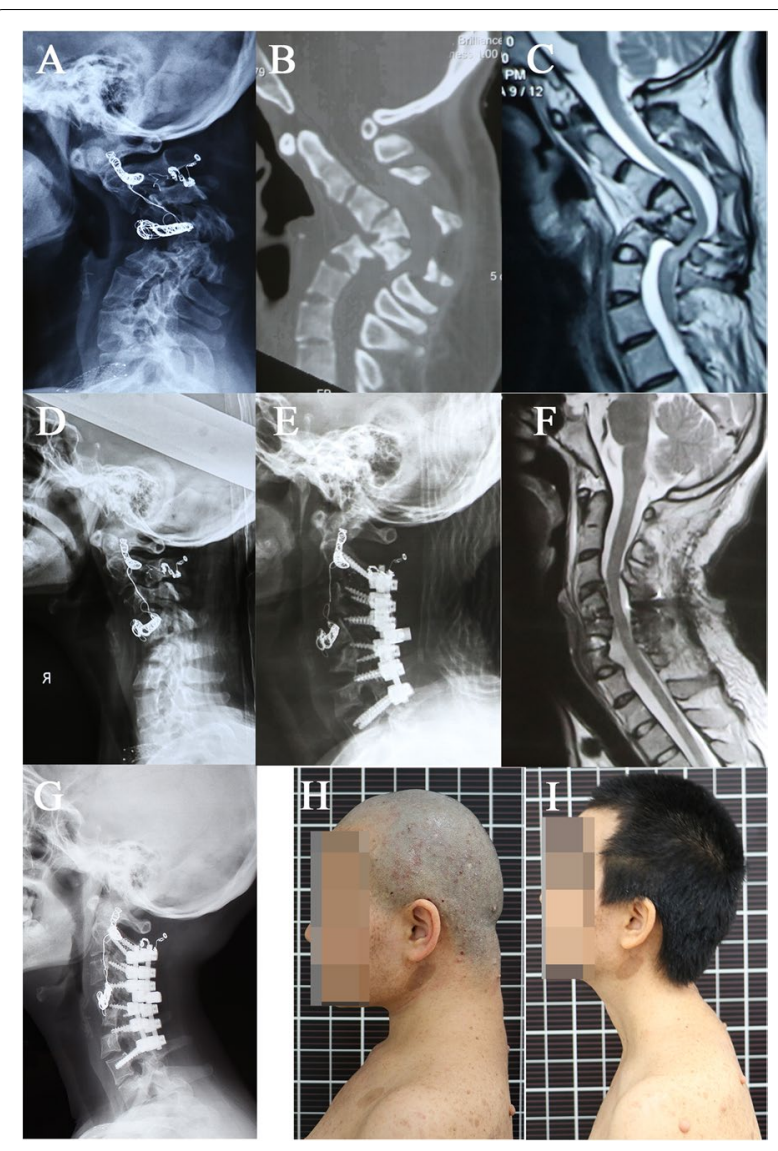

Fig. 2 A 29-year-old case with NF-1 cervical kyphosis. Preoperative JOA score was 12. A-C Preoperative X-rays, CT showed severe kyphosis of $86^{\circ}$ with severe dystrophic changes in cervical spine, and MRI demonstrated a mild compression from kyphosis. D After halo-traction, the kyphotic angle gradually improved from $86^{\circ}$ to $45^{\circ}$. E-F Cercical kyphosis improved to $8^{\circ}$ after surgery, and MRI showed the compression of spinal cord which was decompressed. G X-ray showed a solid bone union and no significant correction loss at follow-up. H-I Pre-op and latest follow-up clinical photos

Table 2 Improvement of kyphosis and statistical results

\begin{tabular}{llll}
\hline Parameters & Mean \pm SD & T value & $P$ value \\
\hline Pre-Tc vs. Post-Tc & $61.3 \pm 19.7$ vs. $33.2 \pm 11.2$ & 12.71 & $<0.01$ \\
Post-Tc vs. Post-Op & $33.2 \pm 11.2$ vs. $10.6 \pm 3.7$ & 10.56 & $<0.01$ \\
Pre-Tc vs. Post-Op & $61.3 \pm 19.7$ vs.10.6 \pm 3.7 & 13.90 & $<0.01$ \\
Post-Op vs. Follow-up & $10.6 \pm 3.7$ vs.9.7 \pm 5.2 & 1.68 & 0.11 \\
\hline
\end{tabular}

Table 3 Improvement of JOA score and statistical results

\begin{tabular}{llll}
\hline Parameters & Mean \pm SD & T value & $P$ value \\
\hline Pre-Tc vs. Post-Op & $13.3 \pm 1.6$ vs. 16.2 \pm 0.7 & -11.02 & $<0.01$ \\
Post-Op vs. Follow-up & $16.2 \pm 0.7$ vs. 16.5 \pm 0.6 & -1.895 & 0.07 \\
\hline
\end{tabular}

The application of halo traction for treatment of cervical kyphosis in NF-1 is still controversial despite the use of halo spinal traction being widely used for treating severe spinal deformity [22-26]. Some scholars believed that traction provides a limited improvement of kyphosis $[27,28]$. However, some authors believed that traction was very important adjuvant treatment for cervical kyphosis. Recent studies have further shown the safety and efficacy of halo traction as an operative adjunct procedure for cervical kyphosis correction. Halo traction could provide a slow and gradual correction while the patients were awake, which typically decreased the amount of corrective force that needed to be applied to the cervical spine. With the help of preoperative halo traction, partial correction of the deformity can be achieved to make the surgical procedure easier with less operative risk [21]. In this study, each patient underwent halo traction prior to the correction surgery. $45.8 \%$ traction correction rate was achieved eventually, and the cervical kyphosis was corrected to safe preoperative levels. Our study further proved that halo traction was safe and an effective adjuvant management for cervical kyphosis correction in NF-1.

Compared with several previous studies $[7,8,10,11$, 29-32] (Table 4), halo traction combined PO approach surgery had a better correction. Halo traction provided the first level correction (45.8\%), and surgery provided the second level correction (36.9\%). Halo traction provided safe partial correction, and typically decreased the amount of corrective force that needed during the surgery. Some factors contribute to the high traction correction rate. In this group, most of patients were presented with flexible kyphosis without a rigid facet joint and they underwent prolonged traction (an average of 23.2 days, the maximum of 61 days). The soft tissue and facet joint can be released to the maximum as a result of long time and heavy traction. Additionally, there is no strong muscles and ligaments around cervical vertebrae and longtime hyperextension traction, which provided a continuous forward force in the cervical spine, and contributed to partial correction. Subsequently, intraoperative traction and $\mathrm{PCO}$ (posterior column osteotomy) was performed to provide a safe surgical correction rate and surgical correction rate eventually reached up to $82.7 \%$ via $\mathrm{PO}$ approach.

The complication rate for the management of cervical kyphosis associated with NF-1 has not been well defined. It was considered that surgical correction of cervical kyphosis in patients with NF-1 has one of the highest rates of complications in cervical spine surgery [33]. Postsurgical complications included cutaneous infection, junctional kyphosis, kyphosis progression, fusion failure and pseudarthrosis at final follow-up. 
Table 4 Results of several previous studies

\begin{tabular}{llllllll}
\hline Authors & Year & Case & Pre-OP Cobb & Post-OP Cobb & Traction & Surgical procedure & Correction rate(\%) \\
\hline Yonezawa, l. et al [8] & 2003 & 1 & 72 & 35 & No & ASF + PSF & 51.40 \\
$\begin{array}{l}\text { Laohacharoensombat, W. } \\
\text { et al [29] }\end{array}$ & 2010 & 1 & 120 & 55 & Skull traction & ASF & 54 \\
J.M. Ma et al [30] & 2011 & 8 & 58.5 & 2.5 & No & $540^{\circ}$ comb procedure & 95.7 \\
F.L. Wu et al [1 1] & 2012 & 1 & 125 & 30 & Cervical suspensory traction & ASF + PSF & 76 \\
Kawabata, S. et al [7] & 2013 & 3 & $140 / 81 / 72$ & $50 / 15 / 27$ & Halo-gravity traction & ASF + PSF & $64.3 / 81.5 / 62.5$ \\
Kevin R. Choksey et al [10] & 2015 & 1 & 46 & 28 & No & ASF & 39.1 \\
Y.F. Gu et al [32] & 2018 & 7 & 67.7 & 12.4 & Skull traction & ASF & 83.1 \\
J.C. Wang et al [31] & 2019 & 10 & 82.0 & 27.3 & Skull traction & ASF + PSF & 66.7 \\
\hline
\end{tabular}

However, a previous study from Helenius [33] stated that the risk of complications did not differ significantly according to the surgical approach. Additionally, Preoperative halo traction was not associated with a lower risk of complications (44\% compared with $69 \%$, $p=0.24)$. In this study, the incidence rate of complications was kept in a relatively lower level. Only 3 patients experienced common traction related minor complications, and 1 patient occurred surgical related complications which was fully recovered after reoperation.

Improvement of neurological deficits via $\mathrm{PO}$ approach is a challenge in cervical kyphosis correction. NF-1 may present multiple levels of involvement and is likely to form complicated paraspinal and/or intraspinal tumors. A intraspinal tumors or tumors with nerve root invasion should be resected to achieve nerve decompression, and this procedure should be performed before a manipulation for deformity correction is done [34]. In addition, a progressive deformity can also lead to severe neurological impairment. When a neurological deficit is present in a young patient with NF-1, it is usually caused by increased kyphosis [35]. In this study, neurological deficits were improved to some degree via halo traction combined with PO approach correction. We inferred the following reasons to achieve the improvement of neurological deficits. Firstly, the neurological deficits caused by cervical kyphosis in NF-1 are mainly compression in front of the spine. It could be improved simultaneously with cervical kyphosis through a longtime standard traction. Secondly, the anterior column of the cervical spine is prolonged and the posterior column is relatively shortened via long time hyperextension traction. As a result, the compression in the front of spine can be improved. Thirdly, compression in cervical kyphosis is caused by apical vertebra and adjacent intervertebral disc. Traction can expand the intervertebral space and make intervertebral disc recovery to mean decompression. Also, the tolerance of spinal cord to ischemia and hypoxia was increased via a halo traction to reduce the risks of intra-operative neurological injury. Lastly, Posterior Column Osteotomy (Ponte osteotomy and SPOs) in apical region under intra-operative traction further released facet joint and shortened the posterior column, which decreased traction in the rear of spinal cord. Moreover, postoperative neurological deficit is another issue for cervical kyphosis correction in patients with NF-1. In a systematic literature review, Guzman et al. [36] reported that the prevalence of C5 nerve root palsy was $7.7 \%$ after anterior cervical procedures and $7.8 \%$ after posterior procedures; however, most of the deficits were resolved spontaneously during the 2-year follow-up period. In this study, postoperative neurological deficits occurred only in 1 patient who recovered after a revision surgery. We found that halo traction combined PO approach correction can also reduce the risk of postoperative neurological deficits.

There are some limitations that should be considered. One is the limited sample size of the included patients. The second limitation is that the medium- and long-term follow-up results should be further evaluated.

\section{Conclusion}

This present study revealed that halo traction combined PO approach surgery is a safe and effective method for cervical kyphosis correction in patients with NF-1. Our data indicated that satisfied correction result and successful bone fusion can be achieved via this procedure, and improvement of neurological deficits can also be obtained. Our study suggested that halo traction combined PO approach surgery is another consideration for cervical kyphosis correction in patients with NF-1.

\section{Abbreviations}

NF: Neurofibromatosis; NF-1: Neurofibromatosis-1; AO: Anterior-only; PO: Posterior-only; AP: Combined anterior and posterior; CT: Computed tomography; MRI: Magnetic resonance imaging; JOA: Japanese Orthopaedic Association; PCO: Posterior Column Osteotomy; SEP: Somatosensory evoked potentials; 
MEP: Motor evoked potentials; Pre-Tc: Pre-Traction; Post-Tc: Post-Traction; PostOP: Postoperative; BMD: Bone mineral density.

\section{Acknowledgements}

Not Applicable.

\section{Authors' contributions}

ZZ contributed to the designs and drafted the manuscript. HZ and CG helped the design of the study and participated in the surgeries. $A D, L X$ did the acquisition, analysis, and interpretation of data of the work. All authors read and approved the final version of the manuscript.

\section{Funding}

This study was funded by Natural Science Foundation of Hunan, China (2019JJ80014).

\section{Availability of data and materials}

The datasets analyzed during the current study are not publicly available but are available from the corresponding author on reasonable request.

\section{Declarations}

\section{Ethics approval and consent to participate}

Our research was approved by the ethics department of Xiangya Hospital, Changsha. We have consensus with all participants. We also followed the Declaration of Helsinki and relevant policies in China. Written informed consent was acquired from each of the patients (or their parents and legal guardians) to authorize treatment, imageology findings, and photographic documentation.

\section{Consent for publication}

Written informed consent was acquired from each of the patients (or their parents and legal guardians) to authorize treatment, imageology findings, and photographic documentation. The patients (or their parents and legal guardians) consented to the publication of their pictures as well as their anonymous and clustered data.

\section{Competing interests}

The authors declare that they have no competing interests.

\section{Author details}

${ }^{1}$ Department of Spine Surgery and Orthopaedics, Xiangya Hospital, CentralSouth University, Changsha, China. ${ }^{2}$ National Clinical Research Center for Geriatric Disorder, Xiangya Hospital, Central-South University, Changsha, China.

\section{Received: 9 July 2021 Accepted: 12 November 2021}

\section{Published online: 23 November 2021}

\section{References}

1. Jaremko JL, PJ MM, Torriani M, et al. Whole-body MRI in neurofibromatosis: incidental findings and prevalence of scoliosis. Skelet Radiol. 2012;41(8):917-23. https://doi.org/10.1007/s00256-011-1333-X.

2. Akbarnia BA, Gabriel KR, Beckman E, Chalk D. Prevalence of scoliosis in neurofibromatosis. Spine (Phila Pa 1976). 1992;17(8 Suppl):S244-8.

3. Boyd KP, Korf BR, Theos A. Neurofibromatosis type 1. J Am Acad Dermatol. 2009;61(1):1-14; quiz 15-6. https://doi.org/10.1016/j.jaad.2008.12.051.

4. Tsirikos Al, Saifuddin A, Noordeen MH. Spinal deformity in neurofibromatosis type-1: diagnosis and treatment. Eur Spine J. 2005;14(5):427-39. https://doi.org/10.1007/s00586-004-0829-7.

5. Gardner A, Millner P, Liddington M, Towns G. Translaminar screw fixation of a kyphosis of the cervical and thoracic spine in neurofibromatosis. J Bone Joint Surg Br. 2009;91(9):1252-5. https://doi.org/10.1302/0301620X.91B9.22101.

6. Mesfin A, Bakhsh WR, Chuntarapas T, Riew KD. Cervical scoliosis: clinical and radiographic outcomes. Global Spine J. 2016;6(1):7-13. https://doi. org/10.1055/s-0035-1554776.

7. Kawabata S, Watanabe K, Hosogane N, et al. Surgical correction of severe cervical kyphosis in patients with neurofibromatosis type 1. J
Neurosurg Spine. 2013;18(3):274-9. https://doi.org/10.3171/2012.11. SPINE12417.

8. Yonezawa I, Arai Y, Tsuji T, Takahashi M, Kurosawa H. Anterior fusion and posterior correction of severe cervical kyphosis using pedicle screw fixation in a patient with neurofibromatosis: a case report. J Spinal Disord Tech. 2003;16(5):493-6.

9. Lin T, Shao W, Zhang K, Gao R, Zhou X. Comparison of outcomes in three surgical approaches for dystrophic cervical kyphosis in patients with Neurofibromatosis type. World Neurosurg. 2017. https://doi.org/ 10.1016/j.wneu.2017.11.174.

10. Choksey KR, Modi JV. Are Two Surgeries Necessary for Correction of 1 Deformity- Cervical Kyphosis in Neurofibromatosis?- A Rare Case Report. J Orthop Case Rep. 2015;5(3):60-2. https://doi.org/10.13107/ jocr.2250-0685.310.

11. Wu F, Zhang L, Liu Z, et al. Cervical neurofibromatosis with tetraplegia: management by cervical suspensory traction. Spine (Phila Pa 1976). 2012;37(14):E858-62. https://doi.org/10.1097/BRS.0b013e31824edd1c.

12. Han K, Lu C, Li J, et al. Surgical treatment of cervical kyphosis. Eur Spine J. 2011;20(4):523-36. https://doi.org/10.1007/s00586-010-1602-8.

13. Winter RB. Thoracic lordoscoliosis in neurofibromatosis: treatment by a Harrington rod with sublaminar wiring. Report of two cases. J Bone Joint Surg Am. 1984;66(7):1102-6.

14. Winter RB. JE Lonstein, and M Anderson, Neurofibromatosis hyperkyphosis: a review of 33 patients with kyphosis of 80 degrees or greater. J Spinal Disord. 1988;1 (1):39-49.

15. Sirois JL 3rd, Drennan JC. Dystrophic spinal deformity in neurofibromatosis. J Pediatr Orthop. 1990;10(4):522-6.

16. Parisini P, Di Silvestre M, Greggi T, et al. Surgical correction of dystrophic spinal curves in neurofibromatosis. A review of 56 patients. Spine (Phila Pa 1976). 1999;24(21):2247-53.

17. Hsu LC, Lee PC, Leong JC. Dystrophic spinal deformities in neurofibromatosis. Treatment by anterior and posterior fusion. J Bone Joint Surg Br. 1984;66(4):495-9.

18. Antonio JR, Goloni-Bertollo EM, Tridico LA. Neurofibromatosis: chronological history and current issues. An Bras Dermatol. 2013;88(3):329-43. https://doi.org/10.1590/abd1806-4841.20132125.

19. Lammert M, Kappler M, Mautner VF, et al. Decreased bone mineral density in patients with neurofibromatosis 1. Osteoporos Int. 2005;16(9):1161-6. https://doi.org/10.1007/s00198-005-1940-2.

20. Tsirikos Al, Ramachandran M, Lee J, Saifuddin A. Assessment of vertebral scalloping in neurofibromatosis type 1 with plain radiography and MRI. Clin Radiol. 2004;59(11):1009-17. https://doi.org/10.1016/j.crad. 2004.04.006.

21. Han X, Sun W, Qiu Y, et al. Halo Gravity Traction Is Associated with Reduced Bone Mineral Density of Patients with Severe Kyphoscoliosis. Biomed Res Int. 2016;2016:8056273. https://doi.org/10.1155/2016/ 8056273.

22. Mehrpour S, Sorbi R, Rezaei R, Mazda K. Posterior-only surgery with preoperative skeletal traction for management of severe scoliosis. Arch Orthop Trauma Surg. 2017;137(4):457-63. https://doi.org/10.1007/ s00402-017-2642-x.

23. Kulkarni AG, Shah SP. Intraoperative skull-femoral (skeletal) traction in surgical correction of severe scoliosis $\left(>80^{\circ}\right)$ in adult neglected scoliosis. Spine. 2013;38(8):659-64. https://doi.org/10.1097/BRS.0b013e3182 $77 c 874$.

24. Zhang HQ, Gao QL, Ge L, et al. Strong halo-femoral traction with wide posterior spinal release and three dimensional spinal correction for the treatment of severe adolescent idiopathic scoliosis. Chin Med J (Engl). 2012;125(7):1297-302. https://doi.org/10.3760/cma.j.issn.0366-6999. 2012.07.020.

25. Zhang $H Q$, Wang $Y X$, Guo $C F$, et al. Posterior-only surgery with strong halo-femoral traction for the treatment of adolescent idiopathic scoliotic curves more than 100 degrees. Int Orthop. 2011;35(7):1037-42. https://doi.org/10.1007/s00264-010-1111-8.

26. Hamzaoglu A, Ozturk C, Aydogan M, et al. Posterior only pedicle screw instrumentation with intraoperative halo-femoral traction in the surgical treatment of severe scoliosis (> 100 degrees). Spine. 2008;33(9):979-83. https://doi.org/10.1097/Brs.0b013e31816c8b17.

27. Ward BA, Harkey HL, Parent AD, RA MG Jr, Kendig RJ. Severe cervical kyphotic deformities in patients with plexiform neurofibromas: case report. Neurosurgery. 1994;35(5):960-4 discussion 964. 
28. Steinmetz MP, Stewart TJ, Kager CD, Benzel EC, Vaccaro AR. Cervical deformity correction. Neurosurgery. 2007;60(1 Supp1 1):S90-7. https:// doi.org/10.1227/01.NEU.0000215553.49728.B0.

29. Laohacharoensombat W, Wajanavisit W, Woratanarat P. Cervical neurofibromatosis with quadriparesis: management by fibular strut graft. Indian J Orthop. 2010;44(1):95-7. https://doi.org/10.4103/0019-5413.54968.

30. Ma J, Wu Z, Yang $X$, Xiao J. Surgical treatment of severe cervical dystrophic kyphosis due to neurofibromatosis type 1: a review of 8 cases. J Neurosurg Spine. 2011;14(1):93-8. https://doi.org/10.3171/2010.9.SPINE 091015.

31. Wang J, Liu C, Wang C, et al. Early and midterm outcomes of surgical correction for severe dystrophic cervical kyphosis in patients with Neurofibromatosis type 1: a retrospective multicenter study. World Neurosurg. 2019;127:e1190-200. https://doi.org/10.1016/j.wneu.2019.04.096.

32. Yifei G, Xiaolong S, Yang L, Peng C, Wen Y. Clinical outcomes of anterior correction and reconstruction for neurofibromatosis-associated severe cervical kyphotic deformity. Int Orthop. 2019;43(3):639-46. https://doi. org/10.1007/s00264-018-4050-4

33. Helenius IJ, Sponseller PD, Mackenzie W, et al. Outcomes of Spinal Fusion for Cervical Kyphosis in Children with Neurofibromatosis. J Bone Joint Surg Am. 2016;98(21):e95. https://doi.org/10.2106/JBJS.16.00096.
34. Ito K, Aoyama T, Miyaoka Y, Horiuchi T, Hongo K. Surgical strategies for cervical spinal Neurinomas. Neurol Med Chir (Tokyo). 2015;55(7):557-63. https://doi.org/10.2176/nmc.ra.2014-0421.

35. Yeh $\mathrm{KT}$, Lee RP, Chen $\mathrm{IH}$, et al. Laminoplasty instead of laminectomy as a decompression method in posterior instrumented fusion for degenerative cervical kyphosis with stenosis. J Orthop Surg Res. 2015;10:138. https://doi.org/10.1186/s13018-015-0280-y.

36. Guzman JZ, Baird EO, Fields AC, et al. C5 nerve root palsy following decompression of the cervical spine: a systematic evaluation of the literature. Bone Joint J. 2014;96-B(7):950-5. https://doi.org/10.1302/0301-620X. 96B7.33665.

\section{Publisher's Note}

Springer Nature remains neutral with regard to jurisdictional claims in published maps and institutional affiliations.
Ready to submit your research? Choose BMC and benefit from:

- fast, convenient online submission

- thorough peer review by experienced researchers in your field

- rapid publication on acceptance

- support for research data, including large and complex data types

- gold Open Access which fosters wider collaboration and increased citations

- maximum visibility for your research: over $100 \mathrm{M}$ website views per year

At BMC, research is always in progress.

Learn more biomedcentral.com/submissions 